\title{
Computational fluid dynamics comparison of separation performance analysis of uniform and non- uniform counter-flow Ranque-Hilsch Vortex Tubes (RHVTs)
}

\author{
Adib Bazgir ${ }^{1}$, Nader Nabhani2 ${ }^{2}$ \\ ${ }^{1}$ B.sc of Chemical Engineering, Petroleum University of Technology, Ahwaz 6118958688, Iran \\ ${ }^{2}$ Associate professor of Mechanical Engineering, Petroleum University of Technology, Ahwaz, Iran
}

Corresponding Author Email: nabhani@put.ac.ir

https://doi.org/10.18280/ijht.360229

Received: 17 September 2017

Accepted: 30 March 2018

\section{Keywords:}

divergent vortex tube, convergent vortex tube, Isentropic efficiency ( $\left.\eta_{\text {is }}\right)$, coefficient of performance (COP), CFD

\begin{abstract}
In the present work, uniform and non-uniform cross section vortex tubes have been optimized utilizing straight, convergent $(\varphi)$ and divergent $(\theta)$ hot-tube axial angles. A computational fluid dynamic (CFD) techniques with RNG k- $\varepsilon$ turbulence model was employed to investigate the influence of divergent $(\theta)$ and convergent $(\varphi)$ angles on the flow behavior within the vortex tube. The isentropic efficiency $\left(\eta_{i s}\right)$ and coefficient of performance (COP) of machine was studied under five different divergent angles $(\theta)$, namely 1, 2, 3, 4 and 6 degree, two different convergent angles $(\varphi)$ named 1 and 2 degree adjusted to the hot-tube. In this study, some factors such as axial angle of inlet nozzles, inlet pressure, mass flow rates and number of inlet nozzles as well as the effect of different kinds of inlet gas have been analyzed in detailed in order to optimize the cooling efficiency of vortex tube (straight). The results show that utilizing the divergent hot-tubes increases the isentropic efficiency $\left(\eta_{i s}\right)$ and coefficient of performance (COP) of device for most values of inlet pressures and helps to become more efficient than the other shape of vortex tubes (straight and convergent). Also, helium has shown produces the largest energy separation as a refrigerant.
\end{abstract}

\section{INTRODUCTION}

Ranque-Hilsch vortex tube (RHVT) simply called as vortex tube is a simple device with no moving parts that will convert a pressurized gas of homogeneous temperature in two streams of different temperature, one warmer than the inlet and one cooler simultaneously. As can be seen in Figure. 1, a vortex tube mainly consists of one or more inlet nozzles, a vortex chamber, a cold orifice and a control valve that is located at the hot end. Vortex tube refrigerator has many advantages over the conventional commercial refrigeration devices such as: simplicity, durability, smallness or lightness of weight, low cost, no need of electricity or chemicals, adjustability of temperature and more environmentally friendly [1-4]. Vortex tubes have widely been used in various applications, including heating and cooling applications, drying gases [5], gas liquefaction [6], separation of gas mixture [7], etc. Owing to the attractive advantages of the vortex tube, scientists have utilized various experimental, analytical and numerical to study the transport phenomena in vortex tube science its discovery by Ranque [8] in 1933. Saidi and Valipour [9] experimentally examined the classification of the parameters affecting the operations of vortex tubes. They have designed and studied the thermo-physical parameters such as inlet gas pressure, type of gas and cold gas mass ratio and moisture of inlet gas and the geometrical parameters such as the diameter and length of the main tube, the diameter of the cold outlet orifice and the shape of the entrance nozzle. Valipour and Niazi [10] investigated the influence of uniform curvature of the main tube on the performance of the vortex tube. They concluded that straight and $150^{\circ}$ curved vortex tubes showed higher performance as a refrigerator compared to other angles of curvature. Dincer et al. [11] experimentally investigated the distinction between cold and hot streams of vortex tube with different length to diameter ratios and number of inlet nozzles. It was concluded that the best performance occurs at length to diameter ratio of 15 and for a nozzle number of at least four. Dincer et al. [12] examined four types of gas (oxygen, carbon dioxide, nitrogen and air) in their experimental work and found that oxygen and air produced nearly the same cold temperature difference. They believed that this phenomenon is related to the specific heat capacity ratio of the gas. The importance of applying types of operating gas in uniform cross section vortex tube, is evaluated by Han et al. [13] (R32, R744, R728, R22, R134a, R161), Pourmahmoud et al. [14] $\left(\mathrm{CO}_{2}\right.$, $\mathrm{NO}_{2}, \mathrm{O}_{2}, \mathrm{~N}_{2}$ and Air), Saidi and Valipour [9] $\left(\mathrm{O}_{2}\right.$, He and Air) and Thakare and Parekh [15]. Hartnett and Eckert [16] measured the velocity, total temperature and total and static pressure distributions inside a uni-flow vortex tube. They used the experimental values of static temperature and pressure to estimate the values of density and concluded that the turbulent eddies were the most important factors of energy separation. Vennous [17] measured the velocity, total temperature, total and static pressures inside a standard vortex tube and reported the existence of substantial radial velocity.

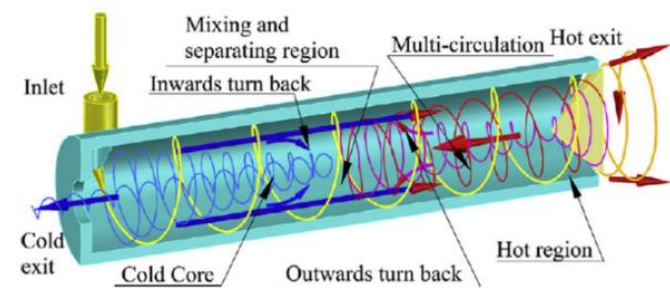

Figure. 1. Flow structure in a counter-flow vortex tube [18] 
Due to limitation of the experimental work, some efforts have been made to successfully utilize computational fluid dynamic (CFD) to find numerical simulations for explanation the fundamental principle behind the energy separation within the vortex tube. Frohlingsdrof et al. [19] by using CFX code along with the $\mathrm{k}-\varepsilon$ model studied fluid flow and energy separation in a vortex tube. Aljuwayhel et al. [20] conducted a two dimensional axisymmetric CFD model to investigate the vortex tube energy separation mechanism and their results proved that their numerical model could predict the temperature separation successfully. Behera et al. [21, 22] presented a three dimensional CFD model for analysis of energy separation using the STAR-CD-Software with the RNG k- $\varepsilon$ turbulence model. Eiamsa-ard [23, 24] carried out a numerical simulation to examine phenomena of the flow field and energy separation inside vortex tube flows. Kazantseva et al. [25] simulated the swirling flow using software CFXTASK. Faruk and Farouk [26] used large eddy simulation to obtain the energy separation inside vortex tube. They compared the predicated results with the published experimental results of Sky et al. [27]. Rafiee and Sadeghizad [28] performed a numerical work to investigate a computational fluid dynamic explanation on a counter-flow air separator using air at the different magnitude of air flow fraction and applying different turbulence models. The results show that among the different methods, the RMS provides the best accurate separation pattern. Rafiee et al. [29] performed an experimental and numerical study on the influenced of shape of throttle valves on the thermal performance of the vortex tube. Four types of hot valve; spherical, plate, cone, and truncated cone were considered. The truncated and spherical valves have shown to have the best thermal performance. Past studies (experimental and numerical) show that using a divergent hot-tube compared with cylindrical one increases the cold temperature difference $\left(\Delta T_{c}\right)$ of the vortex tube but the detailed understanding of flow properties (temperature, velocity, pressure and density distributions) within the divergent vortex tube and its refrigeration capacity (isentropic efficiency $\left(\eta_{i s}\right)$ and coefficient of performance (COP)) remained unclear and already has not been reported. Furthermore, to the best knowledge of the author, no work has been reported on three dimensional numerical comparison among the convergent, straight and divergent vortex tube refrigerators along with analyzing and optimizing the effects of various sorts of inlet gas such as: air, helium, nitrogen and oxygen, axial angle of inlet nozzles, different inlet pressures and mass flow rates, number of inlet nozzles, on the efficiency and performance of the straight vortex tube. The simulation is verified through comparison with the experimental and numerical data reported by Liu et al. [30].

\section{GOVERNING EQUATIONS AND TURBULENCE MODEL}

The compressible turbulent flows in the vortex tubes are determined by solving the conservation of all three equations of momentum, mass and energy. The RNG k- $\varepsilon$ turbulence model is represented to solve the flow complexity. All equations are mentioned below:

$\frac{\partial}{\partial x_{i}}\left(\rho u_{i}\right)=0$
Momentum equation:

$\frac{\partial}{\partial x_{i}}\left(\rho u_{i} u_{j}\right)=-\frac{\partial P}{\partial x_{i}}+\frac{\partial}{\partial x_{j}}\left(\mu\left(\frac{\partial u_{i}}{\partial x_{j}}+\frac{\partial u_{j}}{\partial x_{i}}-\frac{2}{3} \delta_{i j} \frac{\partial u_{k}}{\partial x_{k}}\right)+\right.$

$\frac{\partial}{\partial x_{j}}\left(-\rho \bar{u}_{i} \bar{u}_{j}\right)$

Energy equation:

$\frac{\partial}{\partial x_{i}}\left[u_{i}(\rho E+P)\right]=\frac{\partial}{\partial x_{j}}\left[\left(k_{\mathrm{e}}+\frac{c_{p} \mu_{t}}{P r_{t}}\right) \frac{\partial T}{\partial x_{j}}+u_{i}\left(\tau_{i j}\right)_{e f f}\right]+S_{h}$

$\left(\tau_{i j}\right)_{e f f}=\mu_{e f f}\left(\frac{\partial u_{j}}{\partial x_{i}}+\frac{\partial u_{i}}{\partial x_{j}}\right)-\frac{2}{3} \mu_{e f f} \frac{\partial u_{k}}{\partial x_{k}} \delta_{i j}$

Ideal gas equation:

$P=\rho R T$

We employ the Boussinesq hypothesis [31] to relate the Reynolds stress:

$-\rho \bar{u}_{i} \bar{u}_{j}=\mu_{t}\left(\frac{\partial u_{i}}{\partial x_{j}}+\frac{\partial u_{j}}{\partial x_{i}}\right)-\frac{2}{3}\left(\rho k+\mu_{t} \frac{\partial u_{k}}{\partial x_{k}}\right) \delta_{i j}$

Transport equations for the RNG k- $\varepsilon$ turbulence model are mentioned below:

$\frac{\partial}{\partial x_{i}}\left(\rho k u_{i}\right)=\frac{\partial}{\partial x_{j}}\left(\alpha_{k} \mu_{e f f} \frac{\partial k}{\partial x_{j}}\right)+G_{k}+\rho \varepsilon-Y_{M}$

$\frac{\partial}{\partial x_{i}}\left(\rho \varepsilon u_{i}\right)=\frac{\partial}{\partial x_{j}}\left(\alpha_{\varepsilon} \mu_{e f f} \frac{\partial \varepsilon}{\partial x_{j}}\right)+C_{1 \varepsilon} \frac{\varepsilon}{k} G_{k}-C_{2 \varepsilon}^{*} \rho \frac{\varepsilon^{2}}{k}$

The effective viscosity is acquired by:

$d\left(\frac{\rho^{2} k}{\sqrt{\varepsilon \mu}}\right)=1.72 \frac{\widehat{v}}{\sqrt{\widehat{v}^{3}-1+C_{v}}} d \hat{v}$

$\hat{v}=\mu_{e f f} / \mu, C_{v} \approx 100$

$C_{2 \varepsilon}^{*}=C_{2 \varepsilon}+\frac{C_{\mu} \eta^{3}\left(1-\frac{\eta}{\eta_{0}}\right)}{1+\beta \eta^{3}}$

The definition of production of turbulence kinetic energy is calculated by:

$G_{k}=-\rho \bar{u}_{i} \bar{u}_{j} \frac{\partial u_{i}}{\partial x_{i}}$

The dilatation dissipation term, $Y_{M}$, is included in the $\mathrm{k}$ equation. This term is modeled based on a suggestion by Sarkar [32]:

$Y_{M}=2 \rho \varepsilon M a_{t}^{2} \quad, \quad M a_{t}=\sqrt{\frac{k}{\gamma R T}}$

The model constants are:

$C_{\mu}=0.0845, C_{1 \varepsilon}=1.44, C_{2 \varepsilon}=1.44, \alpha_{k}=\alpha_{\varepsilon}=1.39$

$\operatorname{Pr}_{t}=0.85, \beta=0.012$

Further information and details base on the governing equations and RNG k- $\varepsilon$ turbulence model can be found in ref. [33]. 


\section{OPERATIVE PARAMETERS}

Some parameters which are effective on the performance of vortex tube are defined below:

- Pressure loss ratio:

$\lambda=\frac{\Delta P_{c}}{P_{\text {in }}}=\frac{P_{\text {in }}-P_{C}}{P_{\text {in }}}$

where $P_{\text {in }}(\mathrm{Pa})$ is the total inlet pressure and $P_{c}(\mathrm{~Pa})$ is the total cold outlet pressure which both of them are absolute total pressure.

- Cold mass fraction:

$\xi=\frac{\dot{\mathrm{m}}_{c}}{\dot{\mathrm{m}}_{\text {in }}}$

where $\dot{\mathrm{m}}_{c}(\mathrm{~kg} / \mathrm{s})$ is cold the mass flow rate and $\dot{\mathrm{m}}_{\text {in }}$ $(\mathrm{kg} / \mathrm{s})$ is the inlet mass flow rate.

- Cold temperature difference:

$\Delta T_{c}=T_{\text {in }}-T_{c}$

In which $T_{\text {in }}(\mathrm{K})$ is the inlet air temperature and $T_{c}(\mathrm{~K})$ is the cold air temperature.

- Isentropic efficiency:

According to adiabatic expansion of ideal gas, the refrigeration efficiency of the vortex tubes can be acquired. Base on isentropic expansion in vortex tube, the isentropic efficiency is:

$\eta_{i s}=\frac{\Delta T_{c}}{\Delta T_{i s}}=\frac{T_{i n}-T_{c}}{T_{i n}\left(1-P_{a} / P_{\text {in }}\right)^{\frac{\gamma-1}{\gamma}}}$

where $\eta_{i s}, \Delta T_{i s}(K), P_{i n}$ (bar), $P_{a}$ and $\gamma$ are the isentropic efficiency, isentropic temperature difference, inlet air pressure, atmosphere pressure and specific heat ratio, respectively.

- Coefficient of performance:

By using the principle of isentropic expansion of ideal gas, the coefficient of performance (COP) is calculated by below equation:

$\operatorname{Cop}=\frac{Q_{c}}{W}=\frac{\alpha C_{p}\left(T_{\text {in }}-T_{c}\right)}{\left(\frac{\gamma}{\gamma-1}\right) R T_{\text {in }}\left[\left({ }^{P_{\text {in }}} / P_{c}\right)^{\frac{\gamma-1}{\gamma}}-1\right]}$

In which $Q_{c}$ is cooling rate and $\mathrm{W}$ is mechanical energy which are affected on refrigerating of air inlet.

\section{BOUNDARY CONDITIONS}

The CFD model of the present work is based on the experiment and numerical simulation carried out by Liu et al. [30]. Thus, the boundary condition and initial condition should be determined exactly the same as the actual operating condition. The inlet is defined as pressure inlet, at which the total inlet pressure and temperature are specified for this study, the absolute total inlet pressure and temperature of the compressed air is assumed to vary in range of 0.35 to $0.7 \mathrm{MPa}$ and $298.15 \mathrm{~K}$. The cold and hot fluid outlets are regarded as the pressure outlet condition; the pressure loss ratio $(\lambda)$ is changed by changing both of the total cold and hot pressure outlet. Both absolute total pressure of hot and cold outlets are varied in the range of 0.12 to $0.25 \mathrm{MPa}$ to adjust the pressure loss ratio $(\lambda)$ and the total temperature. The mass flow rate fraction of the cold fluid outlet can vary from 0 to $100 \%$ of the total inlet flow rate by changing the cold and hot outlets.

\section{COMPUTATIONAL DOMAIN AND MODEL SOLVER CONDITIONS}
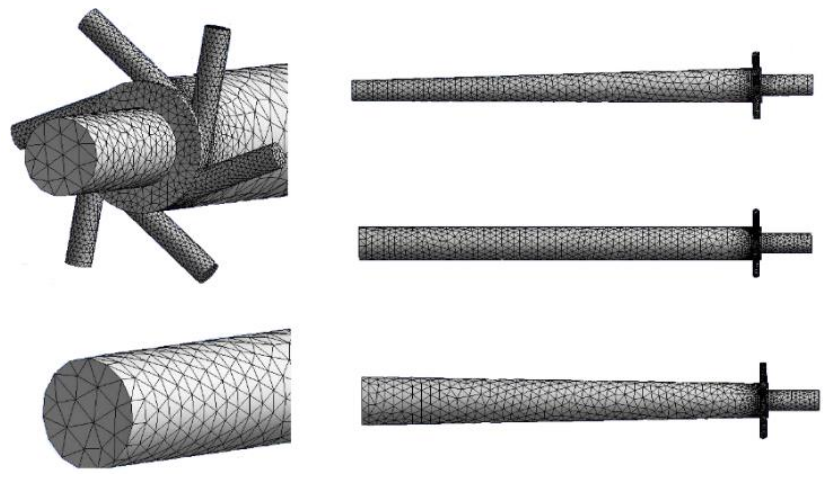

Figure 2. The grids of the three-dimensional model of vortex tubes
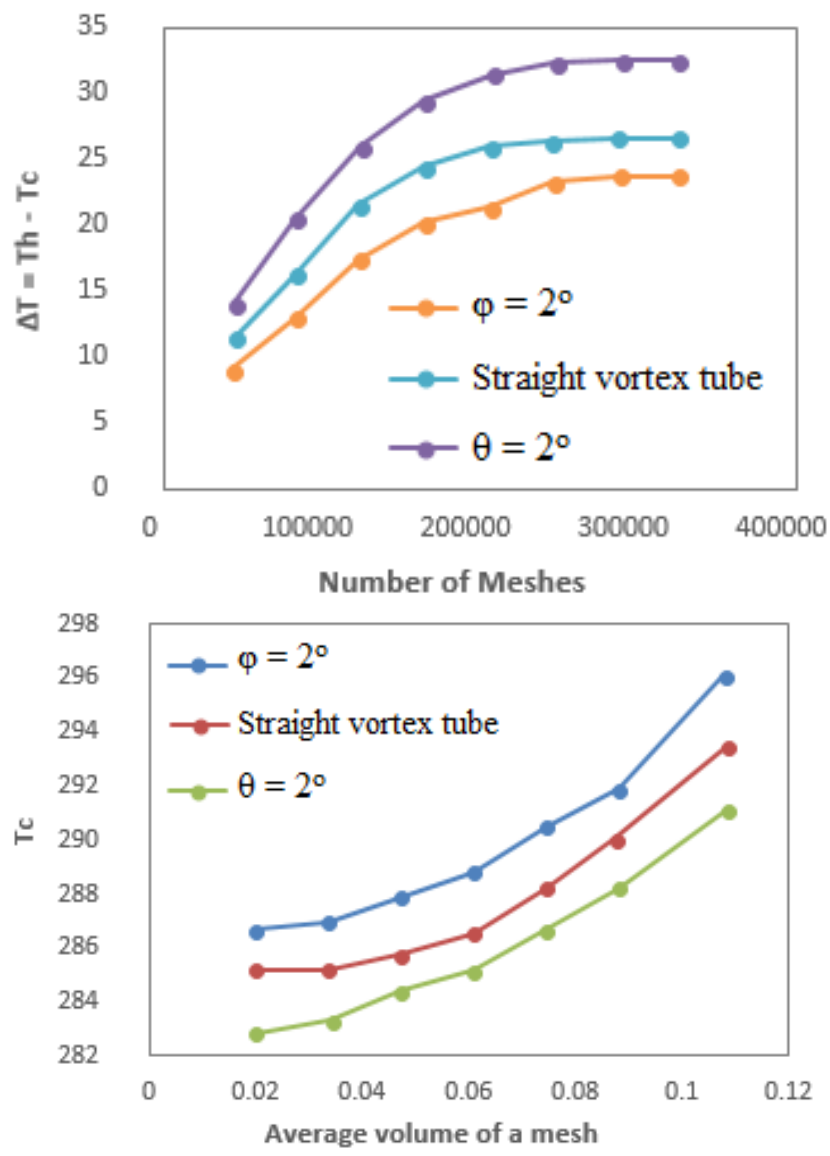

Figure 3. The variations of temperature difference $\left(\Delta \mathrm{T}_{\mathrm{c}}\right)$ versus different number of cells and volume of a mesh for the case $P_{\text {in }}=0.3 \mathrm{MPa}$ 
The calculation domain and the numerical grid for typical geometry are presented. The numerical simulations are performed with the help of ANSYS FLUENT 16.1. The density based, implicit solver is used to solve the governing equations. Third-order MUSCL scheme is used for the convective terms in the momentum, energy and to ignore the displacement terms, QUICK scheme is used for turbulence equations. The under-relaxation is used in all cases for dependent variables. Moreover, the grids of the model for three dimensional of convergent, straight and divergent models are shown schematically in the Figure. 2, indicate that the grid density has a strong influence on the convergence and stability characteristics. The variations of cold temperature difference $\left(\Delta T_{c}\right)$ with number of calculation grid cells are shown in Figure. 3. From Figure. 3, we can see that with the grid more than 280000 cells for three-dimensional convergent $\left(\varphi=2^{\circ}\right)$, straight and divergent $\left(\theta=2^{\circ}\right)$ models, satisfactory results could be ensured.

\section{VALIDATION}

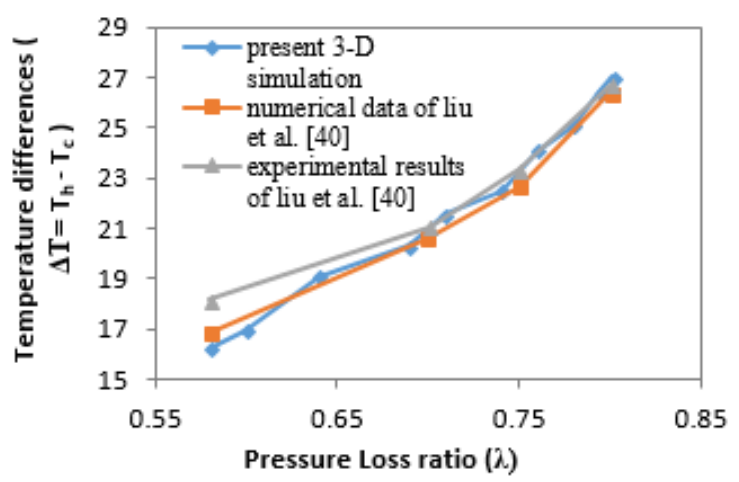

Figure 4. Experimental and numerical variation of total $\left(\Delta T=T_{h}-T_{C}\right)$ temperature difference with pressure loss ratio $(\lambda)$

From Figure. 4, it can be seen clearly that the total temperature difference between the hot and the cold fluid increases almost singularly with the pressure loss ratio $(\lambda)$. This proves that the temperature separation inside the vortex
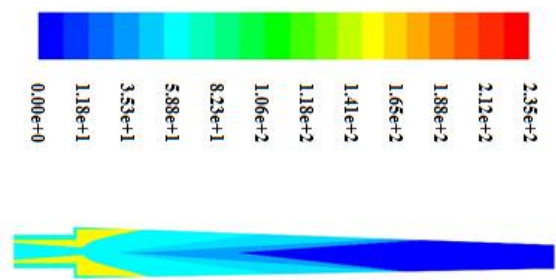

Contour of Tangential Velocity $(\mathrm{m} / \mathrm{s})$ tube is a direct result of pressure loss ratio $(\lambda)$, and the bigger the pressure loss ratio $(\lambda)$, the larger the energy separation is. It can be also seen from Figure. 4 that the numerical and experimental results of Liu et al [30] and present three dimensional simulation agree each other well, which confirms further the reliability of our numerical model and solution method. These aforementioned comparisons highlight the fact that the current numerical model can be used for exploring the general dynamics and temperature separation phenomenon within the vortex tube.

\section{RESULTS AND DISCUSSION}

CFD studies were investigated to verify the existence of secondary circulation phenomenon inside vortex tube, its effect on temperature separation for convergent $(\varphi)$, straight and divergent $(\theta)$ angle values which is comprehensively described in section 7.1. The optimized cold temperature difference $\left(\Delta \mathrm{T}_{\mathrm{c}}\right)$, isentropic efficiency $\left(\eta_{\text {is }}\right)$ and coefficient of performance (COP) for different vortex tubes have been reported in this section. In section 7.2, some thermo-physical parameters have been analyzed and optimized. The investigation has been focused on the various kinds of inlet gas such as: air, helium, nitrogen and oxygen, axial angle of inlet nozzles, different inlet pressures and mass flow rates, number of inlet nozzles as well.

\subsection{Flow properties of vortex tubes}

\subsubsection{Velocity components and flow pattern}

The 3-D velocity profiles within the convergent, straight and divergent vortex tubes are simulated and reported in this work. Owing to the small magnitude of the radial velocity, only the distributions of the total, tangential and axial velocities are shown in Figure. 5 (a-c) for convergent $\left(\varphi=2^{\circ}\right)$, straight and divergent $\left(\theta=2^{\circ}\right)$ vortex tubes, respectively. Total velocity decreases quickly towards the hot end in all vortex tubes and a similar trend can be observed for total velocity profiles in both cases. For the absolute total pressures of $P_{\text {in }}=$ $0.3 \mathrm{MPa}, P_{c}=0.08 \mathrm{MPa}$ and $P_{h}=0.2 \mathrm{MPa}$, the maximum total velocity is about $275 \mathrm{~m} / \mathrm{s}$ at the inlet zone which sharply decreases to zero near the wall.
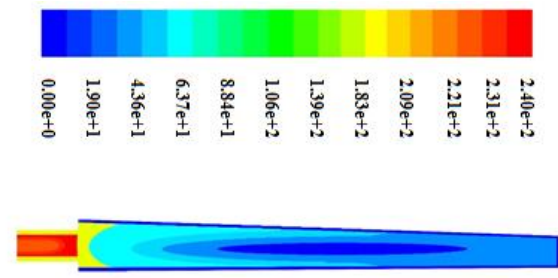

Contour of Total Velocity $(\mathrm{m} / \mathrm{s})$

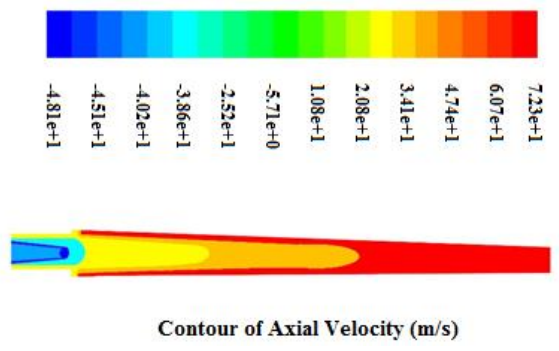

(a) 


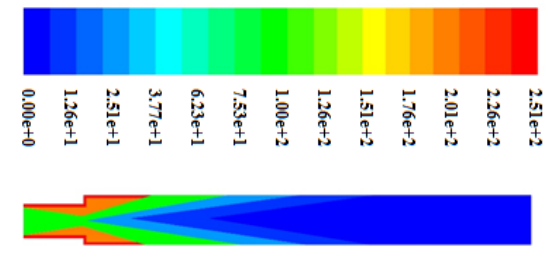

Contour of Tangential Velocity $(\mathrm{m} / \mathrm{s})$
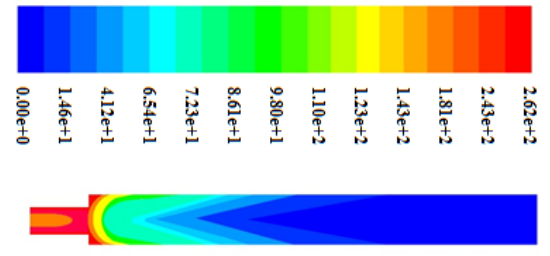

Contour of Total Velocity $(\mathrm{m} / \mathrm{s})$

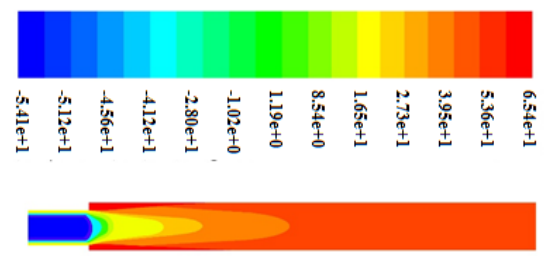

Contour of Axial Velocity $(\mathrm{m} / \mathrm{s})$

(b)

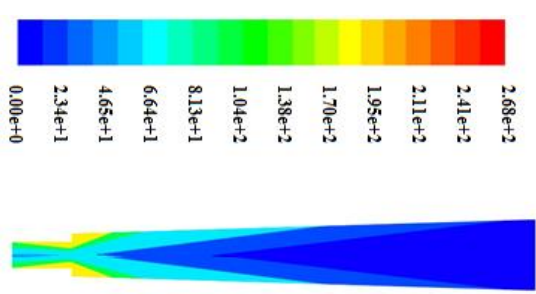

Contour of Tangential Velocity $(\mathrm{m} / \mathrm{s})$
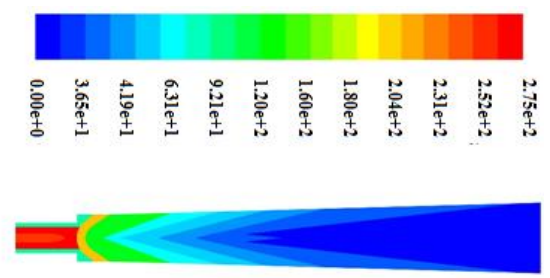

Contour of Total Velocity $(\mathrm{m} / \mathrm{s})$

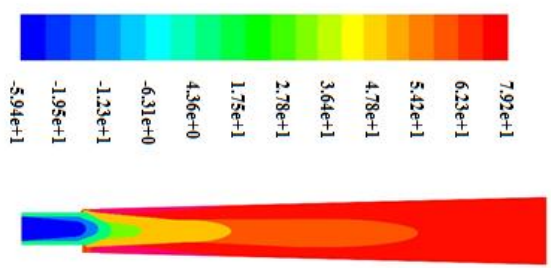

Contour of Axial Velocity (m/s)

(c)

Figure 5. The distributions of the total, tangential and axial velocities of (a) convergent $\left(\varphi=2^{\circ}\right)$, (b) straight and (c) divergent $(\theta$ $=2^{\circ}$ ) vortex tubes at $P_{\text {in }}=0.3 \mathrm{MPa}$ (absolute)

\subsubsection{Density and pressure distributions}

Density and absolute total pressure contours are shown in Figure. $6(\mathrm{a}-\mathrm{c})$ for convergent $\left(\varphi=2^{\circ}\right)$, straight and divergent $\left(\theta=2^{\circ}\right)$ vortex tubes for $P_{i n}=0.3 \mathrm{MPa}$ (absolute). Because the ideal gas is assumed, the density distribution is similar to pressure in the vortex tube. It is clear from these figures that both of the absolute total pressure and density have the maximum values at the inlet zone. Absolute pressure drops from $0.3 \mathrm{MPa}$ at the inlet to nearly $0.107,0.092$ and $0.084 \mathrm{MPa}$ for convergent $\left(\varphi=2^{\circ}\right)$, straight and divergent $\left(\theta=2^{\circ}\right)$ vortex tubes respectively, while the velocity increases very sharply to

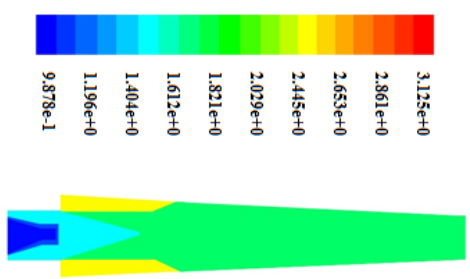

Contour of Density $(\mathrm{kg} / \mathrm{m} 3)$ nearly 240, 262 and $275 \mathrm{~m} / \mathrm{s}$ for convergent $\left(\varphi=2^{\circ}\right)$, straight and divergent $\left(\theta=2^{\circ}\right)$ vortex tubes, respectively (Figure. 5). The density gradient for divergent $\left(\theta=2^{\circ}\right)$ and convergent $(\varphi$ $=2^{\circ}$ ) vortex tubes are the highest and lowest, respectively. Such variance in the density gradient inside vortex tube clearly supports the energy separation (or refrigeration phenomenon). In other words, since divergent $\left(\theta=2^{\circ}\right)$ vortex tube has a higher density gradient compared to straight vortex tube, it causes a stronger centrifugal force which is the main factor for the energy separation.
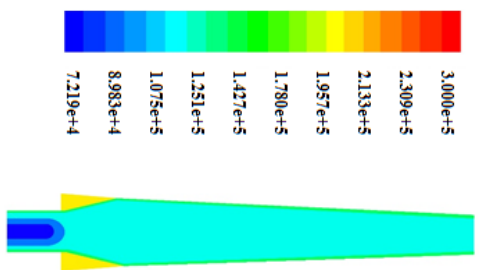

Contour of Total Pressure (Pa)

(a) 

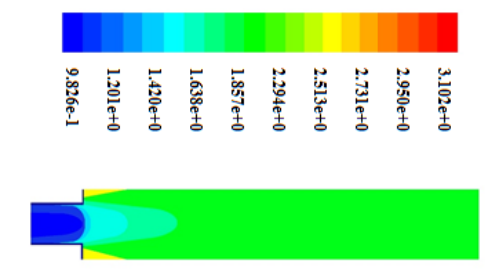

Contour of Density (kg/m3)

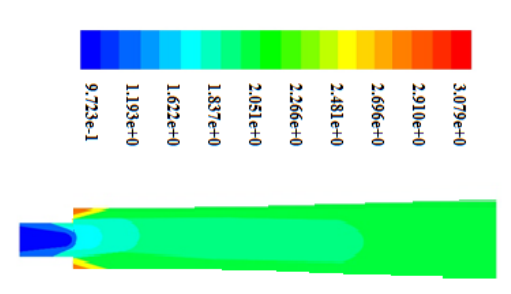

Contour of Density $(\mathrm{kg} / \mathrm{m} 3)$
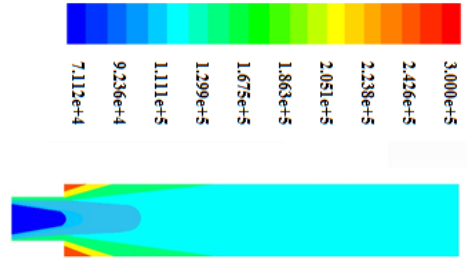

Contour of Total Pressure (Pa)

(b)
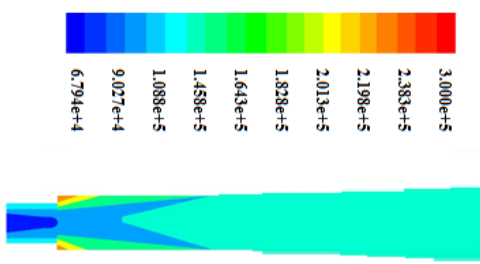

Contour of Total Pressure (Pa)

(c)

Figure 6. Contours of density and total pressure for (a) convergent $\left(\varphi=2^{\circ}\right)$, (b) straight and (c) divergent $\left(\theta=2^{\circ}\right)$ vortex tubes at $P_{\text {in }}=0.3 \mathrm{MPa}$ (absolute)

\subsubsection{Temperature distribution}

For the case of $P_{i n}=0.3 \mathrm{MPa}$ (absolute), Figure. 7 (a-c) shows the distributions of static and total temperature for convergent $\left(\varphi=2^{\circ}\right)$, straight and divergent $\left(\theta=2^{\circ}\right)$ vortex tubes. The maximum total temperatures are $312 \mathrm{~K}, 316 \mathrm{~K}$ and $313 \mathrm{~K}$ for convergent, straight and divergent vortex tubes, while the minimum values are $288 \mathrm{~K}, 285 \mathrm{~K}$ and $283 \mathrm{~K}$

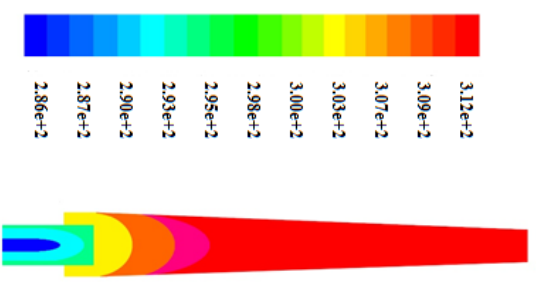

Contour of Total Temperature (K)

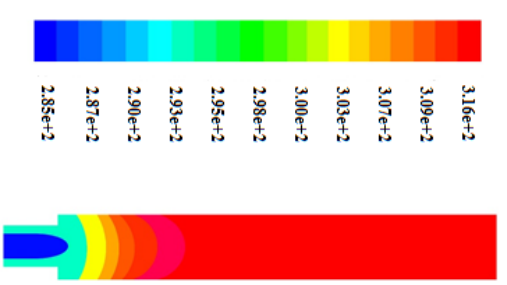

Contour of Total Temperature (K)
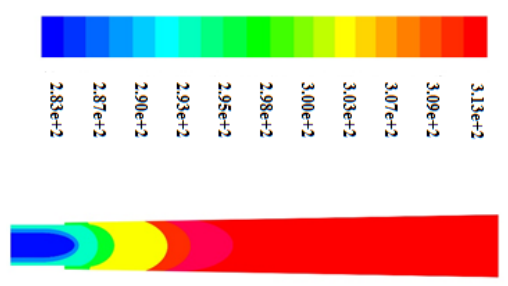

Contour of Total Temperature (K) respectively. These figures show that the temperature drop in vortex tube with cylindrical and convergent hot-tubes is less than the vortex tube with a divergent hot-tube; in addition, for straight, divergent and convergent vortex tubes, the total temperature increases towards the hot exit and decreases around the cold exit.
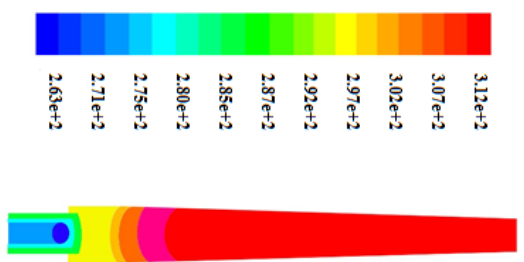

Contour of Static Temperature (K)

(a)

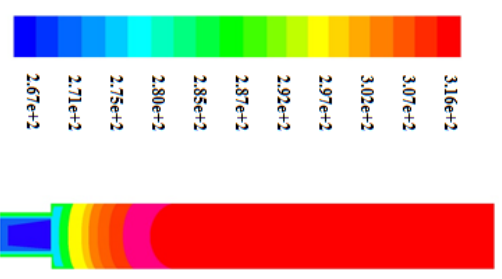

Contour of Static Temperature (K)

(b)
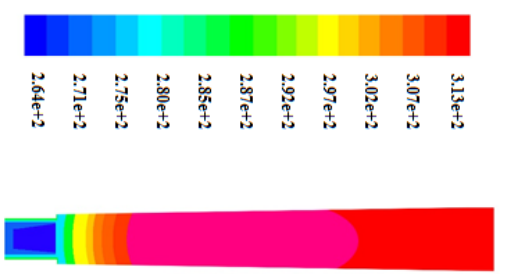

Contour of Static Temperature (K)

(c)

Figure. 7. Contours of total and static temperature respectively for (a) convergent $\left(\varphi=2^{\circ}\right)$, (b) straight and (c) divergent $(\theta=$ $2^{\circ}$ ) vortex tubes at $P_{\text {in }}=0.3 \mathrm{MPa}$ (absolute) 


\subsubsection{Thermal analysis}

Figure. $8(\mathrm{a}, \mathrm{b})$ shows the cold temperature difference $\left(\Delta \mathrm{T}_{\mathrm{c}}\right)$ versus the pressure loss ratio $(\lambda)$ at $P_{\text {in }}=0.3$ and $0.4 \mathrm{MPa}$. The maximum cold temperature difference $\left(\Delta \mathrm{T}_{\mathrm{c}}\right)$ is about 12.1 and $17.8 \mathrm{~K}$ at $\lambda=0.63$ in $P_{\text {in }}=0.3$ and $0.4 \mathrm{MPa}$ for divergent $(\theta=$ $2^{\circ}$ ) vortex tube respectively. The maximum cold temperature difference is 7.2 and $11.2 \mathrm{~K}$ at $\lambda=0.57$ in $\mathrm{P}=0.3$ and $0.4 \mathrm{MPa}$ for convergent $\left(\varphi=2^{\circ}\right)$ vortex tube respectively. It is clear that increasing in the pressure loss ratio $(\lambda)$ can lead to increase in cold temperature difference $\left(\Delta \mathrm{T}_{\mathrm{c}}\right)$ about $\lambda=0.67$. For $0.67<\lambda$ $<0.8$, all divergent vortex tubes have approximately the same cold temperature difference $\left(\Delta \mathrm{T}_{\mathrm{c}}\right)$.

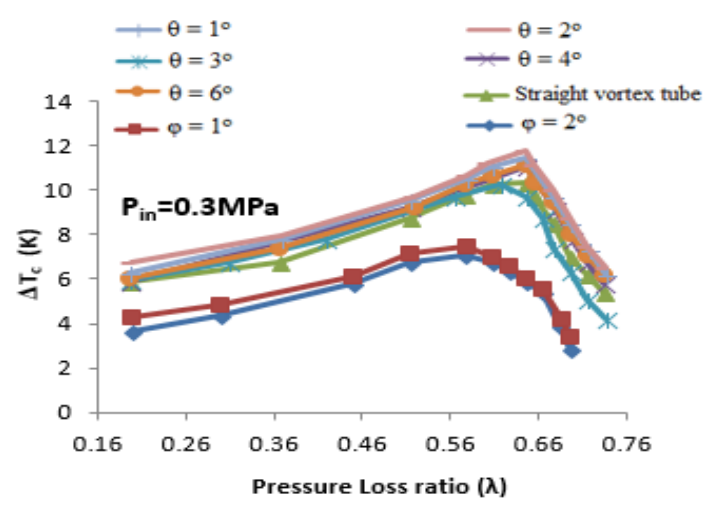

(a)

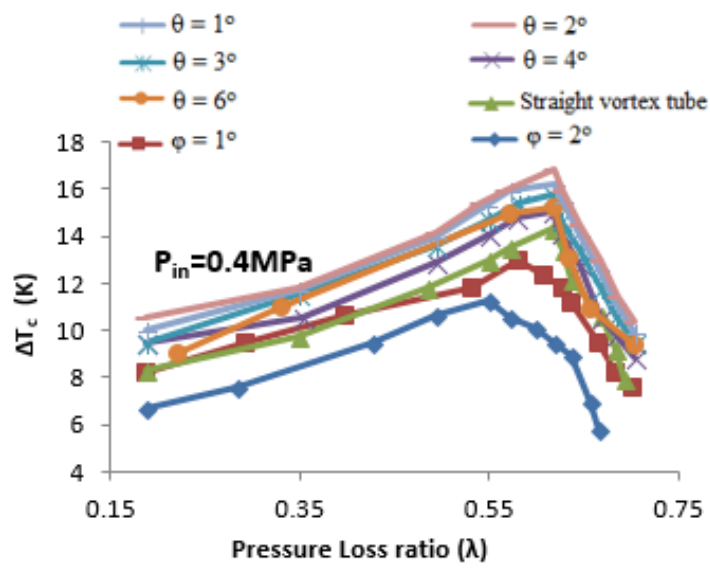

Figure 8. Cold temperature difference $\left(\Delta \mathrm{T}_{\mathrm{c}}\right)$ versus pressure loss ratio $(\lambda)$ for different vortex tubes at (a) $P_{\text {in }}=0.3$ and (b)

$$
P_{\text {in }}=0.4 \mathrm{MPa}
$$

Figure. $9(\mathrm{a}, \mathrm{b})$ represents the effects of divergence and convergence on the efficiency of vortex tubes for different pressure loss ratios $(\lambda)$ at inlet pressures of $P_{\text {in }}=0.3$ and 0.4 MPa. The divergent $\left(\theta=2^{\circ}\right)$ vortex tube has the highest efficiency among the vortex tubes, but the convergent $\left(\varphi=2^{\circ}\right)$ vortex tube has the lowest efficiency among them. The maximum efficiency takes place in the surrounding of $\lambda=0.66$ for all vortex tubes.

By solving the coefficient of performance (COP), the performance characteristics of the vortex tubes have been evaluated. Figure. $10(a, b)$ represents the effects of divergence and convergence on the coefficient of performance (COP) of vortex tubes for various pressure loss ratios $(\lambda)$ at inlet pressures of $P_{\text {in }}=0.3$ and $0.4 \mathrm{MPa}$. For $P_{\text {in }}=0.3 \mathrm{MPa}, 3^{\circ}$ and $4^{\circ}$ divergent $\left(\theta=3^{\circ}\right.$ and $\left.4^{\circ}\right)$ vortex tubes are approximately in the same COP values. Maximum COP value is for divergent $\left(\theta=2^{\circ}\right)$ vortex tube and minimum is for convergent $\left(\varphi=2^{\circ}\right)$ vortex tube. At $0.55<\lambda<0.65$, all divergent and convergent vortex tubes have a maximum COP value.

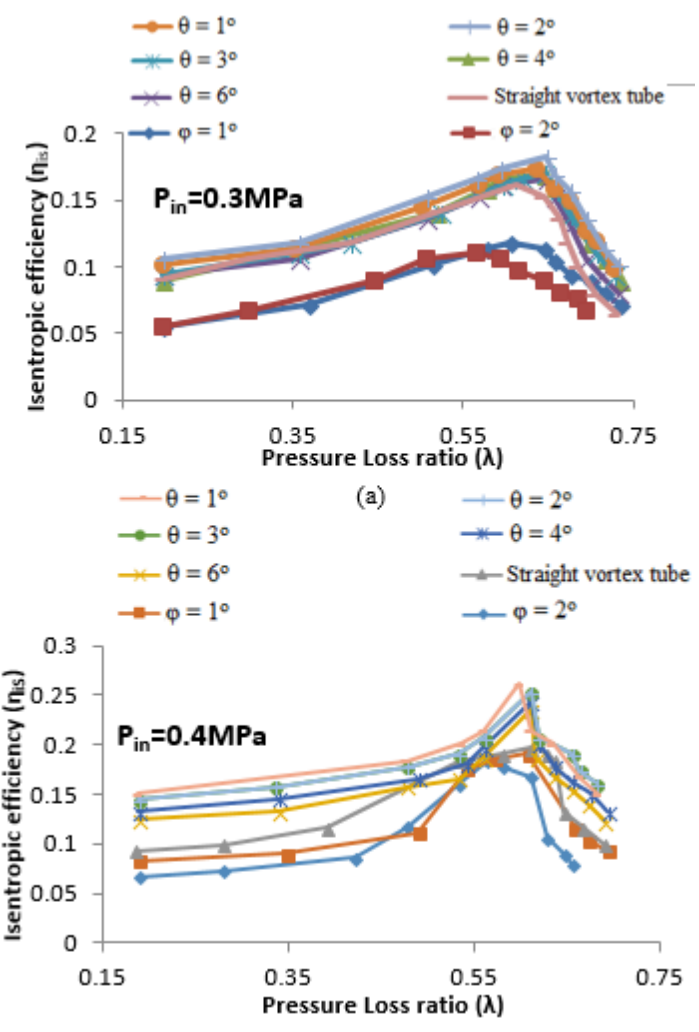

(b)

Figure 9. Isentropic efficiency versus pressure loss ratios $(\lambda)$ for different vortex tubes at (a) $P_{\text {in }}=0.3$ and (b) $P_{\text {in }}=0.4$

$\mathrm{MPa}$

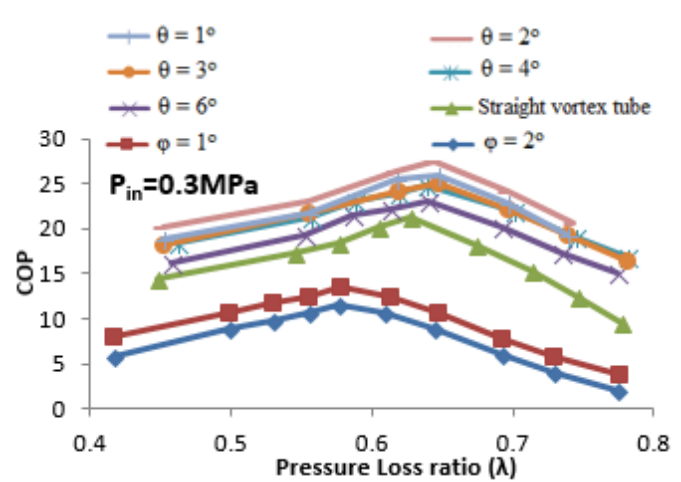

(a)

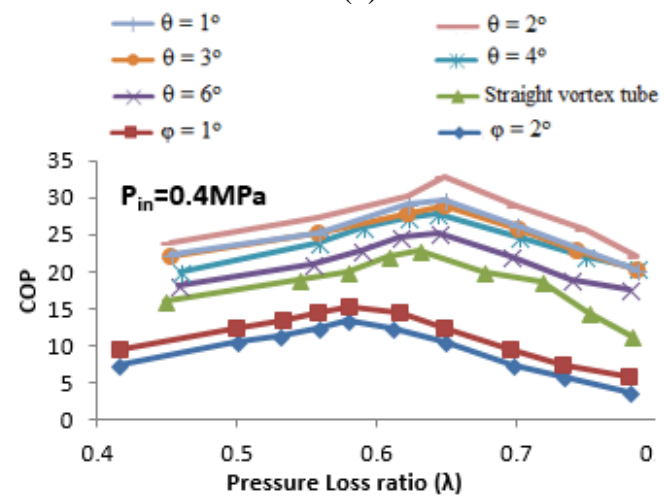

(b)

Figure. 10. Coefficient of performance (COP) versus pressure loss ratios $(\lambda)$ for different vortex tubes at (a) $P_{\text {in }}=$ 0.3 and (b) $P_{\text {in }}=0.4 \mathrm{MPa}$ 


\subsection{Geometric parameters}

\subsubsection{Inlet gas types}

In this section, the effects of different ideal gasses' properties are investigated. Four different ideal gasses are chosen which are called air, oxygen, nitrogen and helium. Both critical parameters of density and specific heat capacity are studied for these ideal gasses in this numerical simulation. According to equation of state for ideal gasses, when density of inlet gas decreases, then pressure also will decrease in all sections inside vortex tube and this can lead to a higher value for velocity. The density variation of different ideal gasses at $P_{\text {in }}=0.4 \mathrm{MPa}$ are shown in Figure. 11.

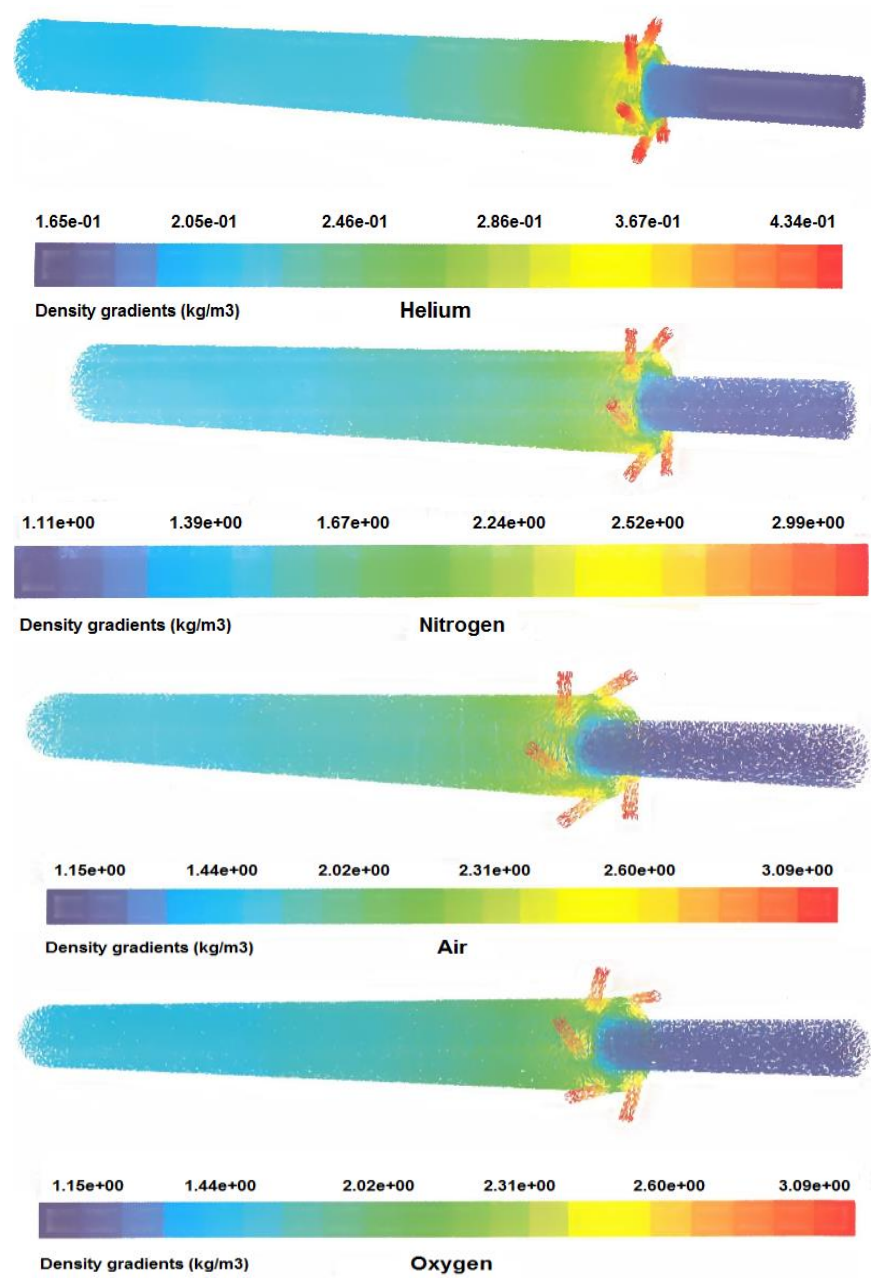

Figure 11. The density variation of different ideal gasses

According to Figure. 11, density of helium as an ideal gas is less than the others. On the other hands, density of oxygen, air and nitrogen are almost the same and it seems that temperature separation for all of them will be the same. Density effects directly on the flow pressure then can effect on velocity magnitude, temperature separation as well. The velocity magnitude of the inlet cross section at $P_{i n}=0.4 \mathrm{MPa}$ is shown for air, oxygen, nitrogen and helium in Figure. 12. It can be seen that the velocity magnitude of helium is more than the others which is shown in Table 1, then it will have the highest temperature separation.

Another parameter which effects on temperature separation is specific heat capacity. At constant pressure, when the specific heat capacity for an ideal gas is the highest value then the flow is more capable to hold its energy than previous and the hot outlet temperature will be increased thus, this can lead to high performance for the vortex tube. Properties of ideal gasses are shown in Table 2.
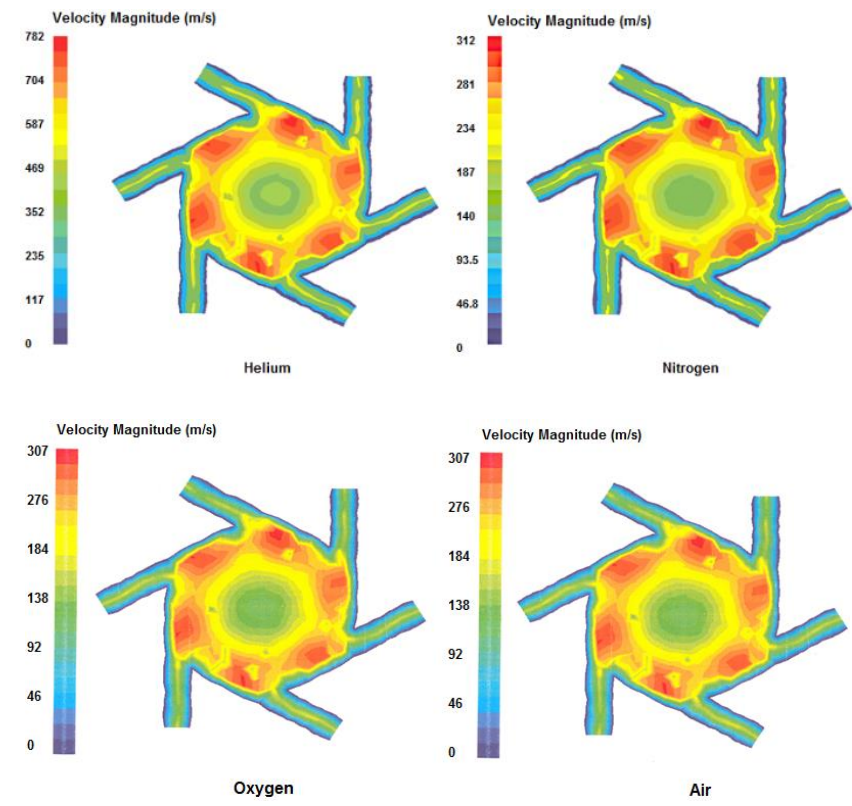

Figure 12. The velocity magnitude contours of the inlet cross sections for air, oxygen, nitrogen and helium

Table 1. Velocity magnitude of different ideal gasses

\begin{tabular}{cc}
\hline Ideal gas & $\begin{array}{c}\text { Maximum velocity magnitude } \\
(\boldsymbol{m} / \boldsymbol{s})\end{array}$ \\
\hline Helium & 782 \\
Nitrogen & 312 \\
Air & 307 \\
Oxygen & 307 \\
\hline
\end{tabular}

Table 2. Properties of ideal gasses

\begin{tabular}{ccc}
\hline Ideal gas & $\begin{array}{c}\text { Density } \\
\left.\mathbf{k g} / \mathbf{m}^{\mathbf{3}}\right)\end{array}$ & $\begin{array}{c}\text { Specific heat capacity } \\
(\boldsymbol{k j} / \mathbf{k g} \cdot \mathbf{K})\end{array}$ \\
\hline Helium & 0.1625 & 5.193 \\
Nitrogen & 1.1213 & 1.041 \\
Air & 1.1614 & 1.007 \\
Oxygen & 1.284 & 0.92 \\
\hline
\end{tabular}

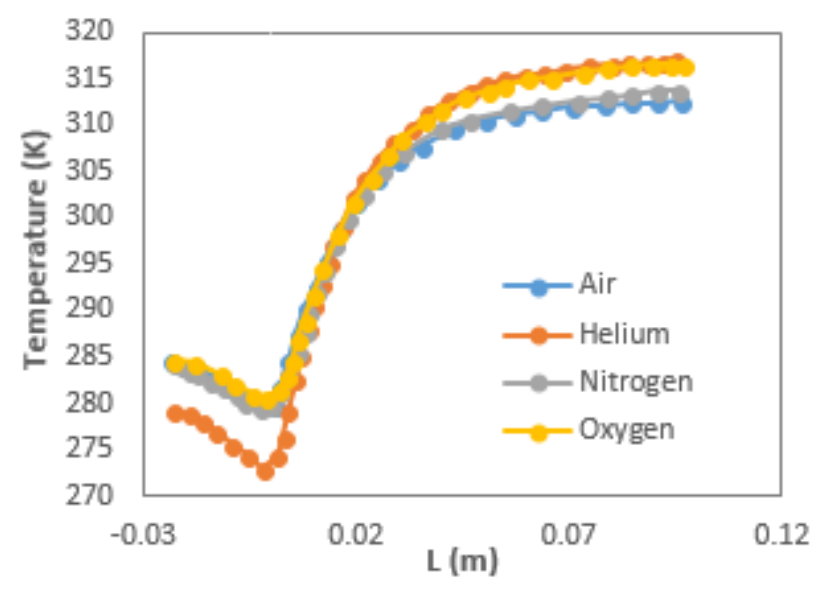

Figure 13. The diagram of temperature versus length of vortex tube for different ideal gasses 
As can be seen, helium has the highest specific heat capacity and lowest density so, it has the higher temperature separation than the others at $P_{\text {in }}=0.4 \mathrm{MPa}$, which is shown in Figure. 13 and more details reported at the same conditions for all ideal gasses in Table 3.

Table 3. Cold and hot temperatures for different ideal gasses

\begin{tabular}{ccc}
\hline Ideal gas & $\begin{array}{c}\text { Cold temperature } \\
(\mathbf{K})\end{array}$ & $\begin{array}{c}\text { Hot temperature } \\
(\mathbf{K})\end{array}$ \\
\hline Helium & 282.17 & 317.95 \\
Nitrogen & 286.61 & 313.44 \\
Air & 286.72 & 313.41 \\
Oxygen & 286.73 & 313.12 \\
\hline
\end{tabular}

6.2.2 Axial angle of inlet nozzle

The effect of axial angle of inlet nozzles on performance of vortex tube is investigated. Four different axial angles $(\alpha)$ are studied such as: $0,3,5$ and 7 degree. A schematic of axial angle $(\alpha)$ of inlet nozzles are shown in Figure. 14.

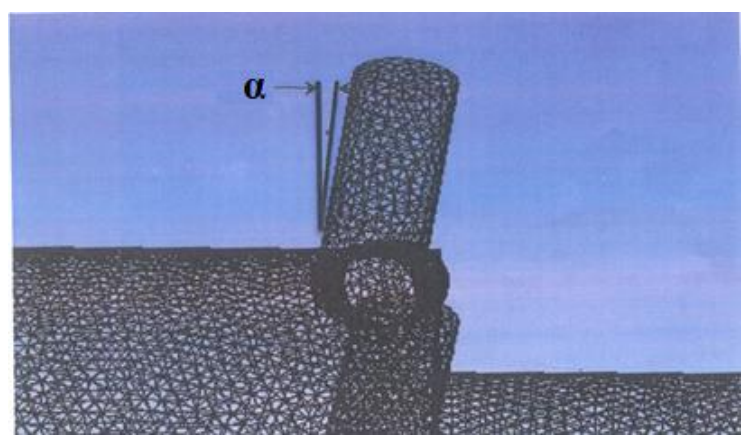

Figure 14. A schematic of axial angle $(\alpha)$ of inlet nozzle

The diagram of temperature versus length of vortex tube at $P_{\text {in }}=0.4 \mathrm{MPa}$ is plotted for analyzing the effect of axial angle magnitude on performance of vortex tube which is shown in Figure. 15.

As can be seen in Figure. 15, by increasing value of axial angle, performance of vortex tube will decrease until 5 degree then it increases for 7 degree and the performance of vortex tube get close to that vortex tube without axial angle of inlet nozzle. The turbulence kinetic energy is an important key parameter for demonstrating temperature separation phenomenon. In Figure. 16, turbulence kinetic energy contours for $\alpha=0,3,5$ and 7 degree at $P_{\text {in }}=0.4 \mathrm{MPa}$ are shown and it predicts that temperature separation will be the maximum value when turbulence kinetic energy will be the least value at critical sections.

As can be observed, for the angle value of 5 degree, the maximum turbulence occurs and it can lead to decrease the performance of vortex tube. In addition, the magnitude of velocity is effective on temperature separation thus, the contours of velocity magnitude at $P_{\text {in }}=0.4 \mathrm{MPa}$ are shown in Figure. 17.

According to Figure. 17, the highest and lowest magnitude of velocity are for those nozzles which enter straight (without axial angle) and has 5 degree of axial angle respectively. Generally investigation the effect of different axial angles of inlet nozzles on performance of vortex tube is important because of two reasons. First, the axial angle influences on the Mach number and may cause some pulses and noisy voices. As can be seen in Figure. 18 for axial angle inlet nozzles vortex tubes at $P_{\text {in }}=0.4 \mathrm{MPa}$, Mach number is less than that vortex tube without axial angle so, the noisy voice can be decreased with a little axial angle of inlet nozzles.
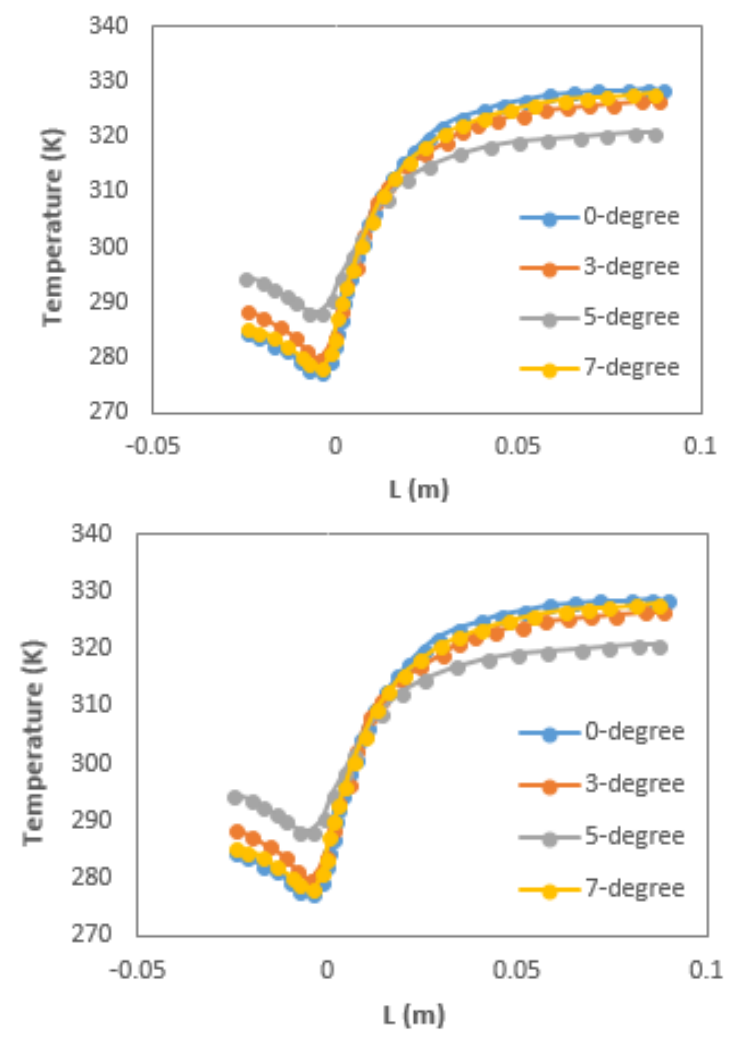

Figure 15. The diagram of temperature versus length of vortex tube for different axial angle inlet nozzles of $\alpha=0,3$, 5 and 7 degrees

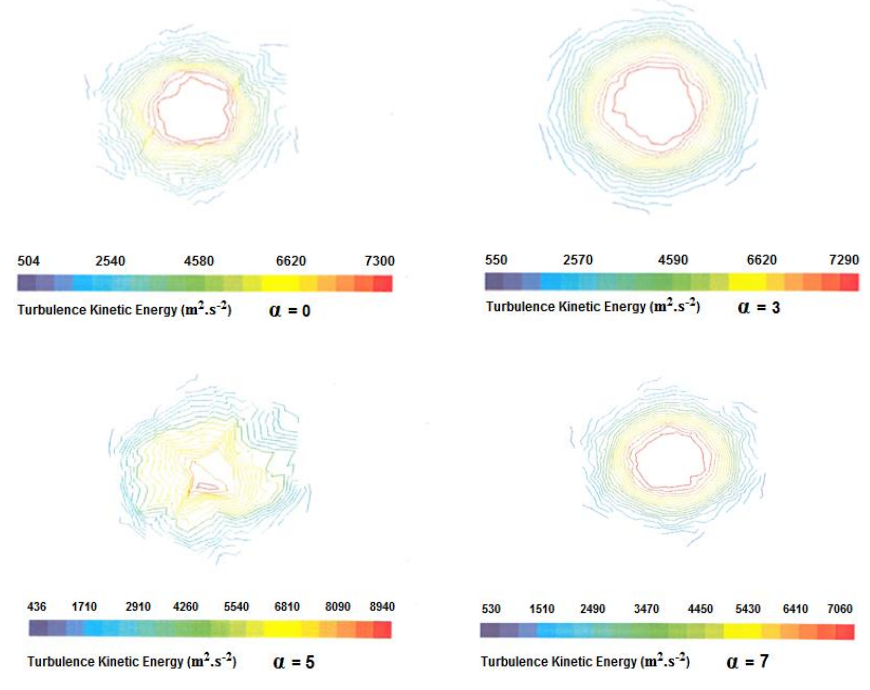

Figure 16. The turbulence kinetic energy contours for $\alpha=0$, 3,5 and 7 axial degree of angle
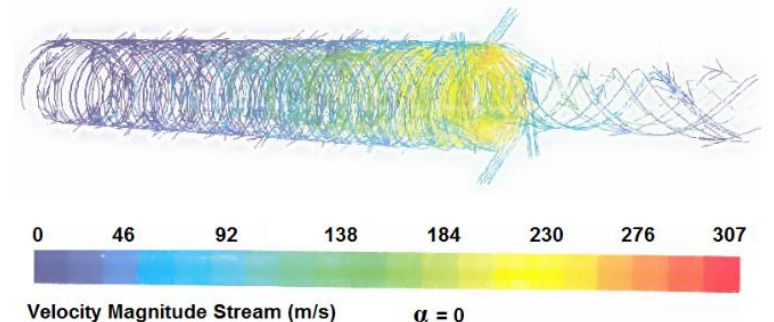


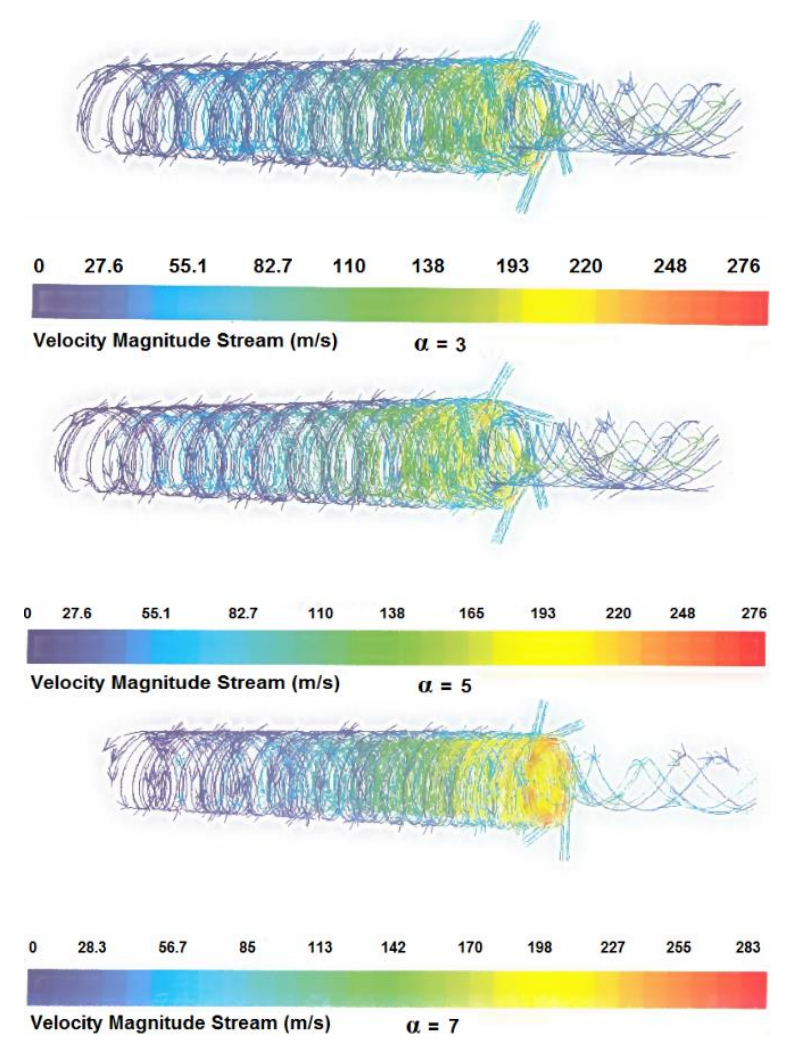

Figure 17. The contours of velocity magnitude for $\alpha=0,3,5$ and 7 axial degree of angle
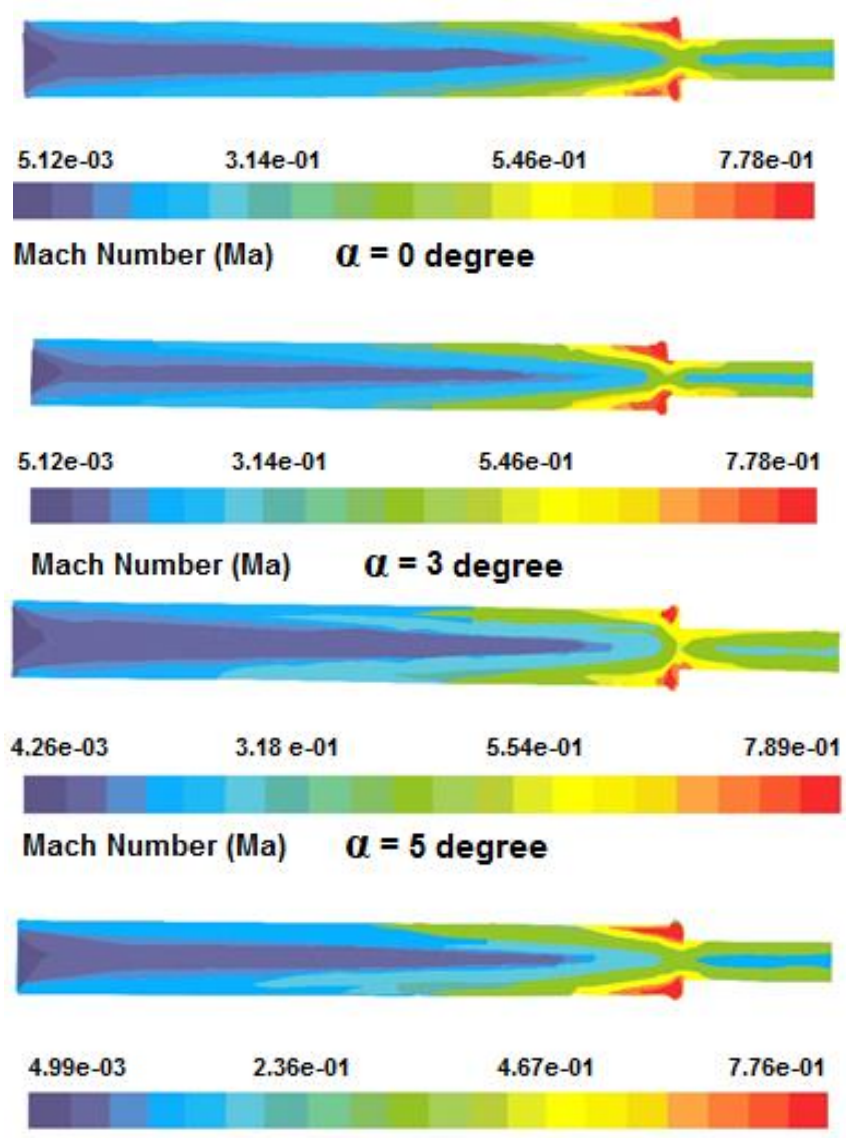

\section{Mach Number (Ma) $\quad \alpha=7$ degree}

Figure 18. The contours of Mach number for $\alpha=0,3,5$ and 7 axial degree of angle
6.2.3 Number of inlet nozzles

The effect of number of inlet nozzle on performance of vortex tube is investigated. Temperature separation and velocity distribution of vortex tube at $P_{i n}=0.4 \mathrm{MPa}$ are shown in Figure. 19 (a, b) respectively. Two, four and six inlet nozzles are investigated for evaluating performance of vortex tube. The most important parameter of creating temperature separation phenomenon is swirling flow inside the vortex tube which is shown schematically in Figure. 19 (b).

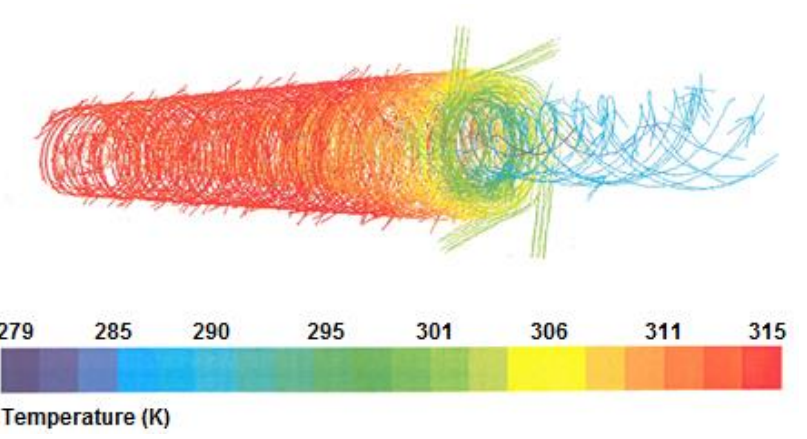

(a)

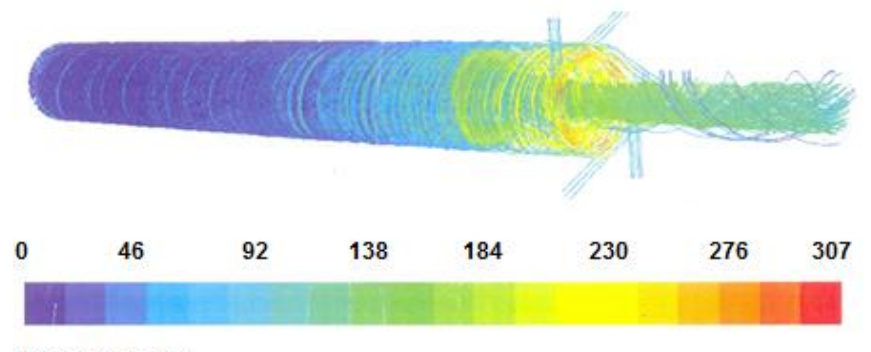

Velocity $(\mathrm{m} / \mathrm{s})$

(b)

Figure 19. The distribution of (a) Temperature and (b) velocity of straight vortex tube

In this study, number of inlet nozzles change but the total inlet surface area will stay a constant value. Thus, when vortex tube has six inlet nozzles, the area surface of each nozzle will be different compared with those four and two nozzles. Information about diameter and area surface of each inlet nozzle are reported in Table 4.

Table 4. Information of different inlet nozzles

\begin{tabular}{ccc}
\hline Number of nozzle & $\begin{array}{r}\text { Diameter of nozzle } \\
(\mathbf{m m})\end{array}$ & $\begin{array}{c}\text { Area of nozzle } \\
\left(\mathbf{m m}^{\mathbf{2}}\right)\end{array}$ \\
\hline Two & 2.285 & 4.1 \\
Four & 1.617 & 2.05 \\
Six & 1.32 & 1.3667 \\
\hline
\end{tabular}

Temperature distribution for two, four and six inlet nozzles vortex tubes at $P_{\text {in }}=0.4 \mathrm{MPa}$ is shown in Figure. 20 . Increasing the number of inlet nozzles can decrease the area surface of each of them, then the velocity of fluid will be increased and swirling flow reaches to the maximum value in every region inside vortex tube.

For analyzing the effect of number of inlet nozzles on temperature separation phenomenon inside vortex tube, the velocity distribution especially tangential velocity gradient should be considered as a key parameter to study and characterize flow behavior inside vortex tube. Velocity vectors for vortex tubes with two, four and six inlet nozzles at $P_{i n}=$ $0.4 \mathrm{MPa}$ are shown in Figure. 21. 


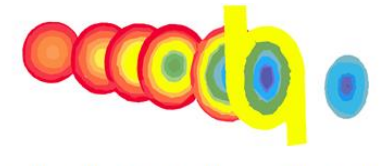

$\begin{array}{llllllllll}278 & 281 & 285 & 288 & 292 & 295 & 302 & 305 & 309 & 312\end{array}$

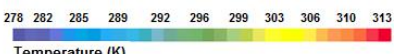
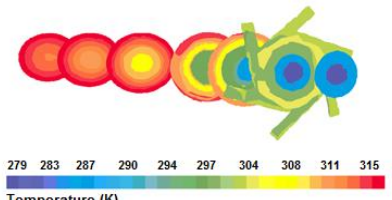

Figure 20. Temperature distribution of two, four and six inlet nozzle vortex tube

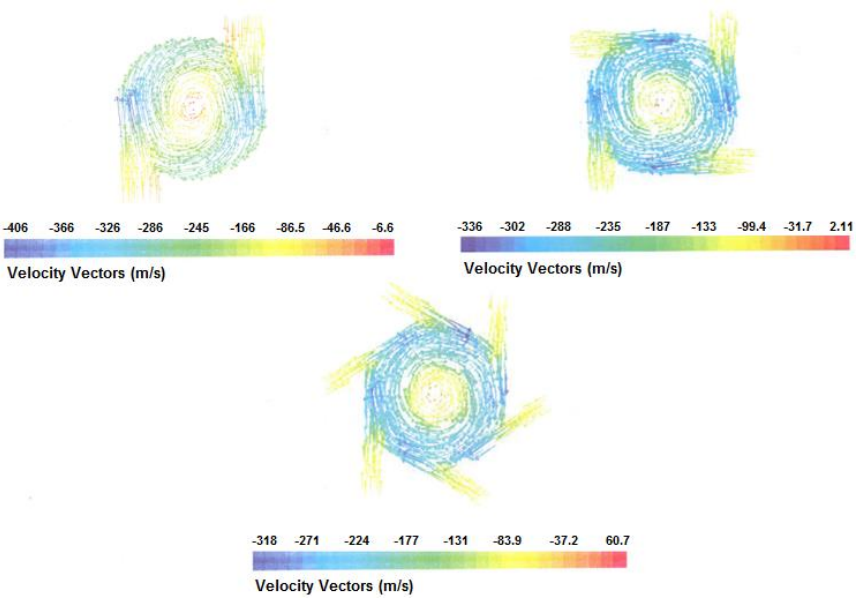

Figure 21. Velocity vectors for vortex tubes with two, four and six inlet nozzles

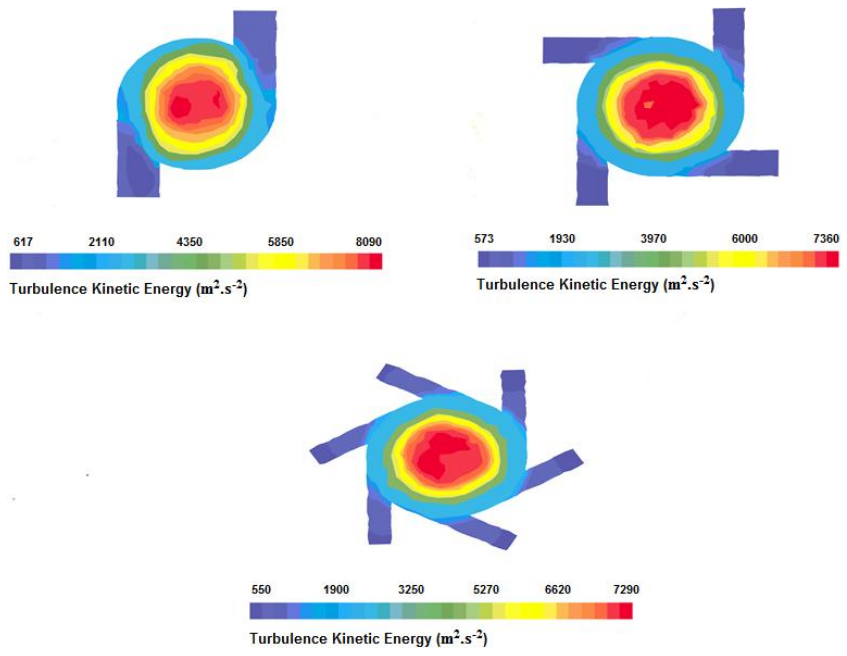

Figure 22. The turbulence kinetic energy of vortex tubes with two, four and six inlet nozzles

Generally when the tangential velocity gradient increases, pressure gradient will increase too then it can lead to more temperature separation. For six inlet nozzles, the tangential velocity is the most predominant velocity gradient and is more than the tangential velocity of vortex tubes with four and two inlet nozzles. One phenomenon reducing the performance of vortex tube is the mixing flow inside vortex tube. When the flow in center of vortex tube is laminar, possibility of creating mixing flow decreases but if the flow is turbulent in the central region of vortex tube then happening of mixing flow and performance of vortex tube will increase and decrease respectively. The turbulence kinetic energy of vortex tubes with two, four and six inlet nozzles at $P_{i n}=0.4 \mathrm{MPa}$ are shown in Figure 22.

Results show that turbulence kinetic energy decreases with increasing number of inlet nozzles because of increasing in tangential velocity that can lead to more temperature separation and increasing the performance of vortex tube. For comparing the temperature separation of different vortex tubes, the diagram of temperature distribution along the axial center line and radial direction in the middle of vortex tubes at $P_{\text {in }}=$ 0.4 MPa are shown in Figure 23 (a, b) respectively. It can be seen that when the number of inlet nozzles increase, temperature separation will be increased too.

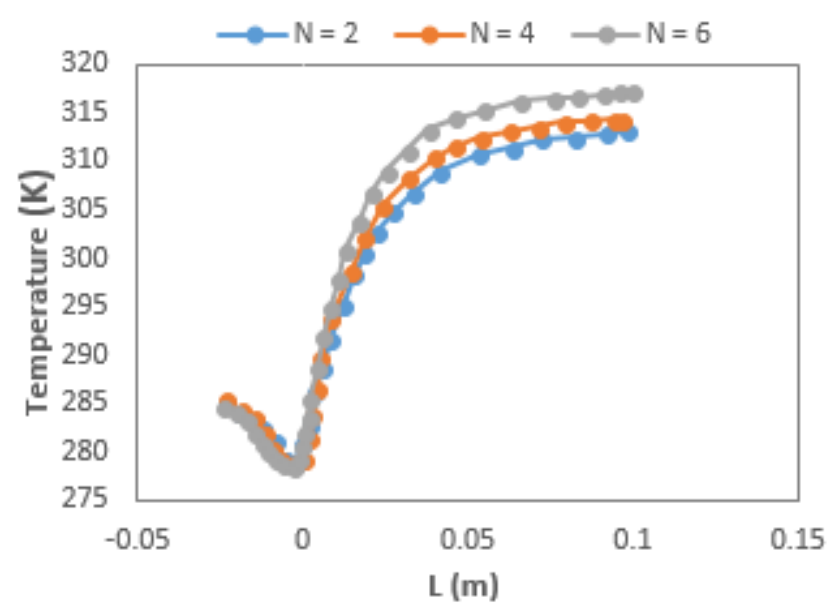

(a)

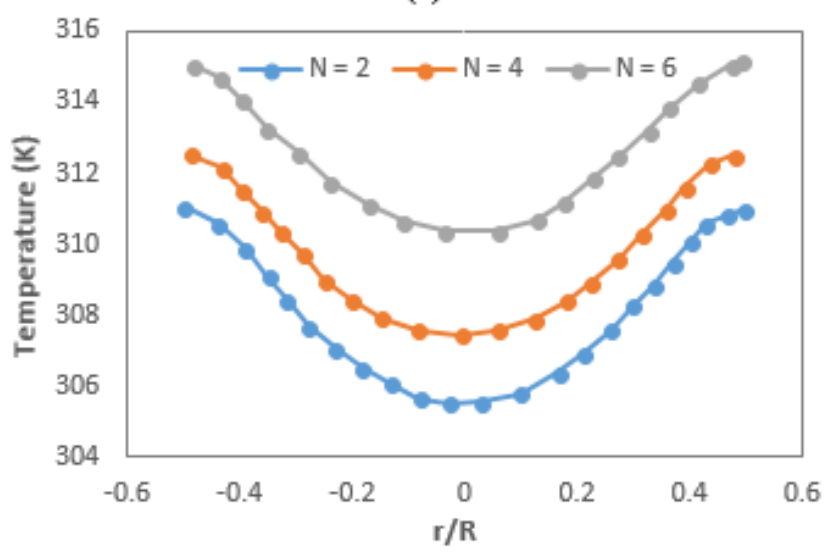

(b)

Figure 23. The diagram of (a) temperature distribution along the axial center line and (b) radial direction at the middle of vortex tube

The temperature separation for vortex tubes with different inlet nozzles at $P_{i n}=0.4 \mathrm{MPa}$ is shown in Table 5 .

Table 5. The temperature information of different inlet nozzles

\begin{tabular}{cccc}
\hline $\begin{array}{c}\text { Number } \\
\text { of } \\
\text { nozzles }\end{array}$ & $\begin{array}{c}\text { Cold } \\
\text { temperature } \\
(\mathbf{K})\end{array}$ & $\begin{array}{c}\text { Hot } \\
\text { temperature } \\
(\mathbf{K})\end{array}$ & $\begin{array}{c}\text { Temperature } \\
\text { difference (k) }\end{array}$ \\
\hline Two & 286.2 & 309.85 & 23.65 \\
\hline Four & 285.76 & 310.986 & 25.226 \\
Six & 285.2 & 313.416 & 28.216 \\
\hline
\end{tabular}




\section{CONCLUSION}

A numerical investigation is performed to examine phenomenon of the flow field and energy separation in the compressible vortex tube flow using the RNG k- $\varepsilon$ model for different convergent $(\varphi)$, straight and divergent $(\theta)$ angles of vortex tubes. The major results of this research paper can be summarized as follows:

The analysis shows that the vortex tube thermal separation phenomenon comes from diffusion process of mean kinetic energy causing high rotating speed motion in vortex tube. There are several parameters can influence on the thermal separation phenomenon and diffusion process such as type of inlet gas including air, helium, nitrogen and oxygen, axial angle of inlet nozzles, different inlet pressures and mass flow rates and number of inlet nozzles.

1. Convergence of vortex tube causes decrease in the swirl velocity and the diffusion process at cold outlet in vortex tube. Results show that the $1^{\circ}$ and $2^{\circ}$ divergent $\left(\theta=1^{\circ}\right.$ and $\left.2^{\circ}\right)$ vortex tubes have higher performance as a refrigerator than other divergent $(\theta)$ and convergent $(\varphi)$ angles.

2. By increasing the number of inlet nozzles, the area surface of every inlet nozzle decreases then this can lead to increase in magnitude of swirling velocity inside vortex tube. Consequently, by increasing swirling velocity, the more temperature separation will happen.

3. According to the major application of vortex tube in temperature separation phenomenon, when the flow inside vortex tube is turbulent especially at critical zone like inlet, the performance of this device will decrease and vice versa.

4. When the inlet nozzles are without axial angle, the turbulence of flow is minimum and the swirling velocity has its maximum value so, the performance of vortex tube will increase.

5. The trend of increasing the axial angle magnitude of inlet nozzle with temperature separation phenomenon is not a linear ascendant function. At the beginning, by increasing the axial angle magnitude of inlet nozzle, the temperature separation decreases then it will have an increasing trend.

6. By increasing the axial angle magnitude of inlet nozzles, the Mach number decreased and dropped down. When the inlet pressure is high, a strong shocking or vibration may occurs inside vortex tube. To prevent this shocking phenomenon, axial angle inlet nozzles vortex tube can be used.

7. Helium has the highest and lowest specific heat capacity and density respectively. Consequently, performance of vortex tube with helium as working fluid is higher than the others.

\section{ACKNOWLEDGMENT}

This paper was partially supported by Petroleum University of Technology (PUT) organization, Department of gas and mechanical engineering of (PUT).

\section{REFERENCES}

[1] Bazgir A. (2017). Ranque-Hilsch vortex tube: A numerical study. 2nd International Conference Of Science and engineering In the Technology Era. Brussels (Belgium).
[2] Bazgir A, Heydari A. (2018). Energy conversion (efficiency) of straight counter-flow Ranque-Hilsch Vortex Tube (RHVT) by using optimized turbulence model. Proceedings of ACN International Conference. Istanbul (Turkey).

[3] Bazgir A. (2017). Investigation of the effects of number of nozzle intakes on the performance of vortex tube refrigerators base on CFD. 6th International Conference on Research in Engineering, Science and Technology. London (England).

[4] Bazgir A. (2017). Numerical investigation of flow pattern inside different counter-flow Ranque-Hilsch vortex tube refrigerators. 3rd International Conference on Innovation In science and Technology, Berlin, Germany.

[5] Pouraria H, Zangooee M. (2012). Numerical investigation of vortex tube refrigerator with a divergent hot tube. Energy Procedia 14: 1554-9. https://doi.org/10.1016/j.egypro.2011.12.1132

[6] Park WG., Pouraria H. (2014). Numerical investigation on cooling performance of Ranque-Hilsch vortex tube. Thermal Science 18(4): 1173-89. https://doi.org/10.2298/TSCI120610052P

[7] Riu KJ, Kim JS, Choi IS. (2004). Experimental investigation on dust separation characteristics of a vortex tube. JSME International Journal Series B Fluids and Thermal Engineering 47(1): 29-36. https://doi.org/10.1299/jsmeb.47.29

[8] Eiamsa-ard S, Promvonge P. (2008). Review of RanqueHilsch effects in vortex tubes. Renewable and Sustainable Energy Reviews 12(7): 1822-42. https://doi.org/10.1016/j.rser.2007.03.006

[9] Saidi M, Valipour M. (2003). Experimental modeling of vortex tube refrigerator. Applied Thermal Engineering 23(15): 1971-80. https://doi.org/10.1016/S13594311(03)00146-7

[10] Valipour MS, Niazi N. (2011). Experimental modeling of a curved Ranque-Hilsch vortex tube refrigerator. International Journal of Refrigeration 34(4): 1109-16. https://doi.org/10.1016/j.ijrefrig.2011.02.013

[11] Dincer K, Baskaya S, Uysal B. (2008). Experimental investigation of the effects of length to diameter ratio and nozzle number on the performance of counter flow Ranque-Hilsch vortex tubes. Heat and Mass Transfer 44(3): 367-73. https://doi.org/10.1007/s00231-0070241-z

[12] Dincer K, Başkaya Ş, Kirmaci V, Usta H, Uysal B. (2006). Investigation of performance of a vortex tube with air, oxygen, carbon dioxide and nitrogen as working fluids. Eng Mach 47(560): 36-40.

[13] Han X, Li N, Wu K, Wang Z, Tang L, Chen G, et al. (2013). The influence of working gas characteristics on energy separation of vortex tube. Applied Thermal Engineering 61(2): 171-7. https://doi.org/10.1016/j.applthermaleng.2013.07.027

[14] Pourmahmoud N, Rafiee S, Rahimi M, Hassanzadeh A. (2013). Numerical energy separation analysis on the commercial Ranque-Hilsch vortex tube on basis of application of different gases. Scientia Iranica Transaction B, Mechanical Engineering 20(5): 1528.

[15] Thakare HR, Parekh A. (2015). Computational analysis of energy separation in counter-flow vortex tube. Energy 85:

62-77. https://doi.org/10.1016/j.energy.2015.03.058 
[16] Eckert E, Hartnett J. (1955). Experimental study of the velocity and temperature distribution in a high velocity vortex type flow. Technical Report No. 6. Minnesota. Univ., Minneapolis. Heat Transfer Lab.

[17] Vennos S. (1968). An experimental investigation of the gaseous vortex: $\mathrm{PhD}$ thesis. Rensselaer Polytechnic Institute. https://doi.org/10.1016/j.rser.2007.03.006

[18] Xue Y, Arjomandi M, Kelso R. (2013). The working principle of a vortex tube. International Journal of Refrigeration 36(6): 1730-40. https://doi.org/10.1016/j.ijrefrig.2013.04.016

[19] Fröhlingsdorf W, Unger H. (1999). Numerical investigations of the compressible flow and the energy separation in the Ranque-Hilsch vortex tube. International Journal of Heat and Mass Transfer 42(3): 415-22. https://doi.org/10.1016/S0017-9310(98)00191-4

[20] Aljuwayhel N, Nellis G, Klein S. (2005). Parametric and internal study of the vortex tube using a CFD model. International journal of refrigeration 28(3): 442-50. https://doi.org/10.1016/j.ijrefrig.2004.04.004

[21] Behera U, Paul P, Kasthurirengan S, Karunanithi R, Ram S, Dinesh K, et al. (2005). CFD analysis and experimental investigations towards optimizing the parameters of Ranque-Hilsch vortex tube. International Journal of Heat and Mass Transfer 48(10): 1961-73. https://doi.org/10.1016/j.ijheatmasstransfer.2004.12.046

[22] Behera U, Paul P, Dinesh K, Jacob S. (2008). Numerical investigations on flow behaviour and energy separation in Ranque-Hilsch vortex tube. International Journal of Heat and Mass Transfer 51(25): 6077-89. https://doi.org/10.1016/j.ijheatmasstransfer.2008.03.029

[23] Eiamsa-ard S, Promvonge P. (2007). Numerical investigation of the thermal separation in a RanqueHilsch vortex tube. International Journal of Heat and Mass $\quad$ Transfer 50(5): 821-32. https://doi.org/10.1016/j.ijheatmasstransfer.2006.08.018

[24] Eiamsa-ard S, Promvonge P. (2008). Numerical simulation of flow field and temperature separation in a vortex tube. International Communications in Heat and $\begin{array}{lll}\text { Mass } & \text { Transfer } & \text { 35(8): }\end{array}$ https://doi.org/10.1016/j.icheatmasstransfer.2008.04.01 0

[25] Kazantseva O, Piralishvili SA, Fuzeeva A. (2005). Numerical simulation of swirling flows in vortex tubes. High Temperature 43(4): 608-13.

[26] Farouk T, Farouk B. (2007). Large eddy simulations of the flow field and temperature separation in the RanqueHilsch vortex tube. International Journal of Heat and Mass $\quad$ Transfer 50(23): 4724-35. https://doi.org/10.1016/j.ijheatmasstransfer.2007.03.048

[27] Skye H, Nellis G, Klein S. (2006). Comparison of CFD analysis to empirical data in a commercial vortex tube. International Journal of Refrigeration 29(1): 71-80. https://doi.org/10.1016/j.ijrefrig.2005.05.004

[28] Rafiee SE, Sadeghiazad MBM. (2016). Threedimensional computational prediction of vortex separation phenomenon inside the Ranque-Hilsch vortex tube. Aviation 20(1): 21-31. https://doi.org/10.3846/16487788.2016.1139814

[29] Rafiee S, Sadeghiazad M. (2017). Experimental and 3D CFD investigation on heat transfer and energy separation inside a counter flow vortex tube using different shapes of hot control valves. Applied Thermal Engineering 110:
648-64.

https://doi.org/10.1016/j.applthermaleng.2016.08.166

[30] Liu X, Liu Z. (2014). Investigation of the energy separation effect and flow mechanism inside a vortex tube. Applied Thermal Engineering 67(1): 494-506. https://doi.org/10.1016/j.applthermaleng.2014.03.071

[31] User's Guide F. 6.3 Documentation. (2006). Fluent Inc, Lebanon, NH.

[32] Sarkar S, Balakrishnan L. (1990). Application of a Reynolds stress turbulence model to the compressible shear layer. 21st Fluid Dynamics, Plasma Dynamics and Lasers Conference. https://doi.org/10.2514/6.1990-1465

[33] Fluent F. 6.3 user's guide. (2006). Fluent Inc.

\section{NOMENCLATURE}

\begin{tabular}{|c|c|}
\hline CFD & Computational Fluid Dynamics \\
\hline $\mathrm{COP}$ & Coefficient of Performance \\
\hline FVM & Finite Volume Method \\
\hline RNG & Renormalized Group \\
\hline $\mathrm{C}_{p}$ & $\begin{array}{l}\text { Specific heat at constant absolute pressure } \\
\left(\mathrm{J} \cdot \mathrm{kg}^{-1} \cdot \mathrm{K}^{-1}\right)\end{array}$ \\
\hline$C_{\varepsilon i}$ & Coefficients $(i=1,2)$ used in $\varepsilon$ equation \\
\hline$C_{\mu}$ & Constants in Eq.13 \\
\hline$C_{v}$ & Constants in Eq.9 \\
\hline$\dot{\mathrm{m}}$ & Total mass flow rate $\left(\mathrm{kg} . \mathrm{s}^{-1}\right)$ \\
\hline $\mathrm{E}$ & Total energy $(\mathrm{kJ})$ \\
\hline$G_{k}$ & Generation of turbulence kinetic energy \\
\hline $\mathrm{k}$ & Turbulence kinetic energy $\left(\mathrm{m}^{2} . \mathrm{s}^{-2}\right)$ \\
\hline $\mathrm{k}_{\mathrm{e}}$ & Thermal conductivity $\left(\mathrm{W} \cdot \mathrm{m}^{-1} \cdot \mathrm{K}^{-1}\right)$ \\
\hline $\mathrm{L}$ & Length of the vortex tube (mm) \\
\hline $\mathrm{P}$ & Absolute total pressure $(\mathrm{Pa})$ \\
\hline $\operatorname{Pr}_{t}$ & Turbulent Prandtl number \\
\hline $\mathrm{R}$ & $\begin{array}{l}\text { Specific constant of an ideal gas } \\
(\mathrm{J} / \mathrm{kgmol} \mathrm{K})\end{array}$ \\
\hline $\mathrm{r}$ & Radial distance of vortex tube (mm) \\
\hline$S_{h}$ & Energy Source \\
\hline $\mathrm{T}$ & Temperature $(\mathrm{K})$ \\
\hline $\mathrm{u}_{\mathrm{i}}$ & $\begin{array}{l}\text { Absolute fluid velocity component in i- } \\
\text { direction }(\mathrm{m} / \mathrm{s})\end{array}$ \\
\hline $\mathrm{Y}_{\mathrm{M}}$ & Contribution of the fluctuating dilatation \\
\hline$Q_{c}$ & Cooling rate \\
\hline $\mathrm{W}$ & Mechanical energy \\
\hline$\Delta \mathrm{P}$ & Pressure differences $(\mathrm{Pa})$ \\
\hline
\end{tabular}

\section{Greek symbols}

$\begin{array}{ll}\alpha_{k} & \text { Inverse effective Prandtl numbers in Eq.7 } \\ \alpha_{\varepsilon} & \text { Inverse effective Prandtl numbers in Eq.8 } \\ \delta_{i j} & \text { Kronecker delta } \\ \tau & \text { Shear stress }\left(\mathrm{N} \cdot \mathrm{m}^{-2}\right) \\ \left(\tau_{i j}\right)_{e f f} & \text { Deviatoric stress tensor }\left(\mathrm{N} \cdot \mathrm{m}^{-2}\right) \\ \varepsilon & \text { Turbulence dissipation rate }\left(\mathrm{m}^{-2} \cdot \mathrm{s}^{-3}\right) \\ \xi & \text { Cold mass fraction } \\ \mu & \text { Dynamic viscosity }\left(\mathrm{kg} \cdot \mathrm{m}^{-1} \cdot \mathrm{s}^{-1}\right) \\ v & \text { Kinematic viscosity }\left(\mathrm{m}^{2} . \mathrm{s}^{-1}\right) \\ \theta & \text { Angle of divergent hot-tube } \\ \varphi & \text { Angle of convergent hot-tube } \\ \alpha & \text { Axial angle of inlet nozzle } \\ \gamma & \text { Specific heat ratio } \\ \rho & \left.\text { Density (kg.m } \mathrm{m}^{-3}\right) \\ \eta_{0} & \text { Coefficient used in Eq.10 }\end{array}$


$\beta, \eta \quad$ Constants in Eq.10

$\lambda \quad$ Pressure loss ratio

$\eta_{i s} \quad$ Isentropic efficiency

eff Effective

h Hot gas

in Inlet gas

is isentropic

\section{Subscripts}

c

Cold gas

$\mathrm{i}, \mathrm{j}, \mathrm{k}$

n

$\mathrm{t}$

a
Cartesian indicates

nozzle

turbulent

Atmospheric 